PIVETTA, C.I. - Perspectivas sobre la justicia francesa del Antiguo Résimen

\title{
Perspectivas sobre la justicia francesa del Antiguo Régimen en las reescrituras del caso La Pivardière de E. T. A. Hoffmann y W. Alexis
}

[Perspectives about French Justice of the Ancien Régime in Hoffmann's and Alexis' rewritings of the case La Pivardière]

http://dx.doi.org/10.11606/1982-8837223751

\begin{abstract}
Both Ernst Th. A. Hoffmann and Willibald Alexis rewrite the La Pivardière case in the Berlin of the Restoration, case which took place at the end of the 17th century in France (Hoffmann in 1821 under the title Die Marquise de la Pivardiere, Alexis in 1843 as Der Herr von Pivardiere). Although both rewritings are based on the same source, the cause célèbre of François Richer of 1773 (probably read in a German translation by Hoffmann and certainly consulted among other versions by Alexis), these reworkings differ remarkably: in this work we shall compare these two versions focusing on the depiction of the characters and the construction of the narrator, in order to examine the implications this has on the vision of crime and of the world that underlies each one. Then we shall consider the way in which the context where the action takes place is reconstructed: whereas in Alexis' version that past is seen as an absolute alterity that reinforces by contrast the advantages and progress of the here and now of Alexis' (re)write, in Hoffmann's, the projection of the action to that past time propitiates a recognition of certain alarming tendencies of the present.
\end{abstract}

Keywords: Criminal Case; Justice; History; Alexis; Hoffmann.

Resumen: Tanto Ernst Th. A. Hoffmann como Willibald Alexis reescriben en el Berlín de la Restauración el caso La Pivardiere, ocurrido a fines del siglo XVII en Francia (aquel en 1821 bajo el título Die Marquise de la Pivardiere; en 1843 como Der Herr von Pivardiere este); si bien ambas reescrituras se basan en la misma fuente, la causa célebre de François Richer de 1773 (probablemente leída en una traducción alemana por Hoffmann y ciertamente consultada junto con otras versiones por Alexis), estas reelaboraciones difieren notablemente: en este trabajo compararemos las narraciones mencionadas centrándonos en la caracterización de los personajes y la construcción del narrador, con la intención de indagar las implicancias que esto tiene en la visión de la criminalidad y del mundo que subyace a cada una; luego examinaremos cómo se reconstruye en cada caso el contexto en el que sucede la acción: mientras que en la versión de Alexis ese pasado es visto como alteridad que refuerza por contraste las ventajas y los progresos del aquí y ahora desde el que se (re)escribe, en la de Hoffmann la proyección de la acción a esa época pretérita propicia un reconocimiento de ciertas tendencias alarmantes del propio presente. Palabras-clave: caso criminal; justicia; historia; Alexis; Hoffmann.

\footnotetext{
${ }^{1}$ Universidad de Buenos Aires, Avenida 25 de mayo, 221, C2001ABD, Buenos Aires, Argentina. E-mail: carolapivetta@ hotmail.com. ORCID: 0000-0002-1955-8456
}

(cc) BY-NC 
PIVETTA, C.I. - Perspectivas sobre la justicia francesa del Antiguo Régimen

\section{Reescrituras de un caso intrincado}

La historia del falso crimen del señor de la Pivardière es un proceso jurídico real que ha sido reescrito en innumerables ocasiones desde que en 1735 el abogado francés François Gayot de Pitaval lo narrara en el tercer tomo de sus Causes célèbres et intéressantes, avec les jugements qui les ont décidées. En el presente trabajo compararemos dos versiones decimonónicas de aquel caso ocurrido en las postrimerías del siglo XVII: Die Marquise de la Pivardiere (1821), de E. T. A. Hoffmann, y Der Herr von Pivardiere (1697-1701) (1843), de W. Alexis (aparecida en el cuarto tomo de Der neue Pitaval, que este coedita junto con J. E. Hitzig). En primer lugar, estudiaremos cuáles son y qué sentido tienen las innovaciones introducidas por cada uno de estos escritores a partir del hipotexto principal, esto es, la reelaboración que hace en 1773 el jurisconsulto francés François Richer, colega e imitador de Gayot de Pitaval, en el cuarto tomo de una obra que titula igual que la de su predecesor, en la que reúne reescrituras de casos ya compilados por este con otros nuevos más recientes. En segundo lugar, indagaremos qué visión y qué valoración de la justicia francesa del Antiguo Régimen se deduce de las dos narraciones cotejadas, a fin de establecer, comparando a su vez con otras historias de crímenes de los mismos autores que también transcurren en la Francia del siglo XVII (Das Fräulein von Scuderi, de Hoffmann; Die Marquise de Ganges, incluida también en la compilación que coeditan Alexis y Hitzig), cómo funciona en cada versión la reconstrucción de ese lugar y ese momento histórico en relación con el presente alemán de la Restauración.

Antes de comenzar con el cotejo, conviene recapitular algunos datos centrales del caso en cuestión. Su singularidad radica en que el presunto crimen que desencadena una serie de denuncias y acciones judiciales en realidad nunca ha tenido lugar; se trata del asesinato del señor de la Pivardière, por el cual se acusa a la señora de la Pivardière y a su confesor Charost, en cuyo presunto affaire amoroso se cree encontrar el móvil para explicar el pretendido complot criminal. Si bien no pasa mucho tiempo hasta que el propio Louis de la Pivardière se presenta ante los tribunales para refutar con su presencia los cargos contra su esposa, esto no alcanza per se para demostrar la inocencia de la imputada ni la de su aparente cómplice: la reaparición del "asesinado" da origen, en cambio, a un nuevo y extenso proceso emprendido para dilucidar si se trata o no de un impostor. Si bien después de cuatro años sale por fin a la luz la inocencia de los sospechosos, una vez que la maquinaria judicial que se ha puesto en marcha es difícil detenerla: varios procesos

Pandaemonium, São Paulo, v. 22, n. 37, mai.-ago. 2019, p. 51-75 
PIVETTA, C.I. - Perspectivas sobre la justicia francesa del Antiguo Régimen

se desarrollan en simultáneo, superponiéndose, incluso contradiciéndose e invalidándose en ciertos puntos. Dado que intervienen distintos tribunales, que juzgan por cierto asuntos incompatibles como lo son el asesinato y la existencia de la misma persona, se plantean además controversias de incumbencia y validez en torno a lo actuado por cada uno de ellos.

El esclarecimiento de este embrollado affaire requiere pues tomar en consideración las circunstancias previas al delito, que permiten comprender por qué, la noche en que el marido recién llegado a su castillo, tras una fría recepción de su esposa presenciada por varios invitados a cenar, se esfuma dejando allí sus botas, su abrigo, su pistola y su caballo, se desatan rumores de que ella lo ha asesinado, habladurías en las que se basa la posterior imputación. Para reconstruir esta prehistoria tanto las versiones del siglo XVIII como las del XIX que consideraremos presentan datos comunes sobre la vida de los protagonistas. Así, en todas ellas se informa que Louis de la Pivardière nace en una familia noble, aunque sin fortuna (falta de medios agravada en su caso porque es el benjamín de tres hermanos); que se casa con Françoise Marguerite de Chauvelin y pasa así a ser señor de las tierras y el castillo de Nerbonne, única herencia de su mujer, propiedad donde ambos se establecen y escenario de los hechos juzgados; que se ausenta por largos períodos en cumplimiento de las obligaciones militares contraídas como oficial al servicio de Luis XIV, lo cual lleva al enfriamiento de una relación conyugal que, de todos modos, según mencionan todas las versiones, nunca estuvo basada en una especial inclinación ni afecto mutuo; que la señora de la Pivardière entabla un asiduo contacto con el prior de la abadía de Miseray, situada en las cercanías de Nerbonne, quien pronto asume también las funciones de capellán del castillo y confesor de su propietaria; que el oficial renuncia, pasado cierto tiempo, a su cargo y vuelve a casarse, bajo el nombre falso de Du Bouchet, con una muchacha de Auxerre, pueblo donde forma una nueva familia y ocupa el cargo de ujier, que queda vacante tras la muerte de su suegro; finalmente, que los apuros económicos del bígamo lo llevan a emprender fugaces regresos al castillo de su esposa legítima (quien naturalmente ignora estos cambios), en busca de los medios para mantener su segundo hogar.

Hasta aquí hemos resumido a grandes rasgos las principales coincidencias argumentales entre las reescrituras mencionadas del caso. En las diferencias que es posible detectar entre ellas se centrará nuestro análisis, que procurará en primer lugar establecer los diversos modos en que estos hechos "reales" son vueltos a narrar por 
PIVETTA, C.I. - Perspectivas sobre la justicia francesa del Antiguo Régimen

Hoffmann y Alexis, iluminando las alteraciones respecto de lo trasmitido por Gayot de Pitaval y Richer, para poder a continuación interpretar el sentido de las innovaciones realizadas por cada uno.

\section{Hoffmann: el desenmascaramiento del mundo al revés}

La novela corta de E. T. A. Hoffmann “Die Marquise de la Pivardiere (Nach Richer's Causes Célèbres)" aparece en 1821 en el Taschenbuch zum geselligen Vergnügen, editado por Enoch Richter. La narración se abre con una conversación, mantenida en un círculo aristocrático, sobre un asunto de actualidad, el asesinato a puñaladas de una mujer a manos de su esposo, “[e]in Mensch gemeinen Standes, Namens Barré” (1985: 730), ocurrido en los bosques de Boulogne. A partir de los comentarios que suscita este fait divers se desata una controversia acerca de los factores causantes de la criminalidad. La duquesa d'Aiguillon, anfitriona de la velada, atribuye el violento delito cometido por ese hombre harto de su esposa y atraído por otra mujer a la falta de educación así como de principios éticos y religiosos del pueblo llano. Esta opinión es refutada por el conde de Saint-Hermine, quien asegura que Barré está lejos de ser un hombre ignorante o impío (sabe escribir, es bien dotado para los números, ayuna y se confiesa tal como su religión manda); luego, y como para terminar de desbaratar el argumento de la duquesa, el cabizbajo conde, saliendo de su inhabitual ensimismamiento, comunica a los allí reunidos el asesinato del marqués de la Pivardière, que atribuye sin vacilar a la esposa de este. Dado que la supuesta asesina es una vieja conocida de los departientes -y en algunos casos incluso amiga íntima-, la noticia impacta en el auditorio y corta en seco la animada charla. La historia enmarcada que se narra a continuación, al revelar al mismo tiempo que la inocencia de la acusada, la hipocresía y la doble vida de la supuesta víctima de este crimen apócrifo, deja en evidencia que la depravación moral que lleva a delinquir no puede ser explicada con un argumento tan simplista como el expuesto por la duquesa. Por cierto, el diagnóstico de esta elocuente dama que se arroga, así como a los de su misma condición social, una superioridad ética y se cree más allá del crimen queda desenmascarado como prejuicio de clase. ${ }^{2}$ El caso La Pivardière, tal como lo reelabora

\footnotetext{
${ }^{2}$ El narrador toma expresamente distancia de la opinión de la duquesa: "Die Duchesse verlor sich gern in moralische Betrachtungen, und so entwickelte sie auch jetzt mit vieler Beredsamkeit, daß nur heillose Vernachlässigung des Unterrichts und der Religiosität bei dem gemeinen Volk Verbrechen erzeuge, die den höhern, in Geist und Gemüt gebildeten Ständen fremd bleiben müßten" (1985: 730; el subrayado es nuestro).
}

Pandaemonium, São Paulo, v. 22, n. 37, mai.-ąo. 2019, p. 51-75 
PIVETTA, C.I. - Perspectivas sobre la justicia francesa del Antiguo Résimen

Hoffmann, demuestra que el autor no comparte esta explicación de la delincuencia, que coincide con la difundida por la Kriminalgeschichte alemana de la Ilustración tardía (Schiller, Meißner, Müchler); la visión del mundo que se deduce de esta novela corta, de hecho, es ya radicalmente distinta a la ilustrada: puesto que la inmoralidad se ha propagado por todo el tejido social y es un mal extendido al que solo se sustraen unos pocos individuos excepcionales, el delito difícilmente podría explicarse en función de los condicionamientos sociales. La tajante división entre los raros seres que se caracterizan por su pureza moral y una mayoría que cede, en mayor o menor medida, a la depravación generalizada se plasma ya en el matrimonio Pivardière: mientras que el marqués encarna la más profunda corrupción moral, su esposa brilla como modelo de la más absoluta inocencia. De ahí el énfasis en este personaje femenino, a quien Hoffmann convierte en la figura central de su narración, tal como anuncia el título.

Por cierto, la consideración conjunta del título y el subtítulo elegidos por el autor proporciona valiosos indicios para discernir cuál es la impronta particular de esta versión, sobre todo si se conocen otras elaboraciones previas del caso. Pues si el subtítulo ("Nach Richer's Causes Célèbres"), al indicar como fuente la recopilación de fines del siglo XVIII, funciona como una garantía de la verdad de lo narrado, el título ("Die Marquise de la Pivardiere") supone en cambio un tácito alejamiento respecto del hipotexto declarado. Este distanciamiento puede observarse en la presencia de un detalle libremente inventado por el autor, que no se corresponde con los datos que constan en la causa célebre en la que afirma haberse basado: ${ }^{3}$ Hoffmann, como ya observamos, no solo restituye el énfasis en la figura femenina, a la cual Richer al retitular su narración como "Geschichte des Herrn de la Pivardière" (el subrayado es nuestro) había borrado por completo, ${ }^{4}$ sino que además le adjudica a esta la condición de marquesa, dignidad de la cual carece su modelo histórico. Este detalle del título anticipa a su vez la modificación de otras circunstancias biográficas de la ahora protagonista, que en la reescritura hoffmaniana no es viuda ni madre de cinco hijos, sino que se casa tardíamente y en primeras nupcias con el marqués de la Pivardière.

\footnotetext{
${ }^{3}$ Lo más probable, de todos modos, es que Hoffmann haya consultado la traducción alemana de Carl Wilhelm Franz, editada en Jena entre 1782 y 1792 por la editorial Cuno (cf. bibliografía final).

${ }^{4}$ Con este nuevo título, Richer se aparta ostensiblemente de Gayot de Pitaval, que denomina la historia "Histoire de la Pivardière" (nótese que este título poco específico que lleva la causa célebre de 1735 va seguido del siguiente subtítulo, en el que Gayot de Pitaval, al recapitular el quid del caso en cuestión, aclara que la mentada en el título es la mujer: "Femme Accusée d'avoir fait tuer son Mari, qui se justifie en le représentant").
} 
PIVETTA, C.I. - Perspectivas sobre la justicia francesa del Antiguo Régimen

La primera parte del relato enmarcado, una amplificación de la vida pasada de la marquesa, provee precisamente una explicación de por qué esta dama culta y acomodada permanece soltera hasta una edad avanzada. Allí se reconstruye la vida prematrimonial de la que aparece en el marco narrativo como la principal culpable del crimen de su marido, lo cual, como sabemos, pronto se revelará falso. La presentación que el narrador hace de ella se demora especialmente en la crianza y la formación que esta mujer, que queda tempranamente huérfana de madre, recibe de su progenitor. Este "geistreiche[r], aber strenge[r] und ernste[r] Mann" cree que es posible "das weibliche Gemüt zur Erkenntnis seiner eignen Schwäche zu bringen" (ibíd.: 732), por lo cual aísla a su hija desde la infancia de cualquier influencia femenina, impidiéndole el contacto con compañeras de juegos o institutrices y asumiendo él mismo su educación de acuerdo con sus "abscheuliche Grundsätze" (ibíd.: 738). Aunque el caballero de Chauvelin se afana en imprimirle "die Rauhigkeit eines männlichen Geistes, der das Spiel des Lebens verachtet" (ibíd.: 733) y más tarde, en la juventud, dirige "die vernichtenden Pfeile seiner Ironie gegen die süße Schwärmerei der Liebe, die den weiblichen Sinn erst recht nach seiner innersten Bedeutung gestaltet" (ibíd.: 732), el porvenir de la marquesa prueba que “die viel zu gelehrte Bildung, die ihr der Vater gegeben [hat]" (ibíd.: 733) no logra acallar por completo lo que según el autor constituye "das innerste, eigentliche Wesen des Weibes" (ibíd.). Pasando por alto lo mucho que podría decirse sobre la imagen de la mujer delineada en estas consideraciones acerca de la educación femenina y en particular sobre la supuesta "esencia" femenina de la que habla el último pasaje citado, este desvío hacia el pasado añadido por Hoffmann sirve para esclarecer un punto oscuro que contiene el caso real, a saber, la vida amorosa de la señora de la Pivardière y, más específicamente, la índole de su vínculo con el prior de Miseray. Si en todas las versiones anteriores que reconstruyen el caso se insinúa que entre estos dos habría -tal como rumorean los vecinos del castillo de Nerbonne- un affaire prohibido, que provee el móvil del supuesto asesinato, aquí esa relación nunca traspasa los estrechos límites de la decencia, tal como el narrador omnisciente asegura con insistencia (ibíd.: 745, 747). A la hipótesis de un amorío entre ambos, que en esta versión es una mera asunción insidiosa de los personajes que funcionan o bien como exponentes de la maledicencia y el entrometimiento en la vida ajena (François Marsau) o bien de la prevención de la que no están exentos ni siquiera quienes deberían ser modelos de imparcialidad y ecuanimidad (el juez Bonnet), se contrapone la verdadera relación que une aquí a los dos acusados: un amor genuino y

Pandaemonium, São Paulo, v. 22, n. 37, mai.-ago. 2019, p. 51-75 
PIVETTA, C.I. - Perspectivas sobre la justicia francesa del Antiguo Résimen

casto, aunque cercenado apenas nace. La extensa retrospección inicial proporciona entonces los motivos por los cuales no puede desarrollarse libremente el mutuo afecto entre aquella señorita de dieciséis años y el joven con el que ella entra en contacto en el círculo de la duquesa d'Aiguillon, que resultará ser el futuro prior Silvain François Charost. Entre los múltiples impedimentos que frustran ese amor prematuramente interrumpido están no solo las falsas ideas sobre este sentimiento inculcadas por el caballero de Chauvelin a su hija, que hacen que esta reprima el "unbekanntes Feuer" (736) que le despierta el muchacho, sino también las intrigas que tanto su padre como su futuro esposo traman para desbaratar cualquier posible lazo entre los enamorados: el primero impide todo contacto entre ambos, intercepta las cartas que Charost escribe a su hija y falsifica una fría y terminante respuesta de esta; el segundo se hace pasar por amigo del joven enamorado a fin de convencerlo, en connivencia con el padre de la marquesa, de renunciar a su amada y tomar los hábitos, solo para poder seducirla luego él mismo mediante nuevas simulaciones (para conquistarla disfraza el interés económico que lo lleva a pretenderla de coincidencia de opiniones y principios sobre el matrimonio, cuando en realidad solo le interesa usufructuar del patrimonio de ella para hacer frente a sus numerosas deudas). ${ }^{5}$ Gracias a estas exitosas estratagemas, el falso amigo y calculador pretendiente logra contraer matrimonio con la heredera de las tierras de Nerbonne, trece años después de aquel primer y frustrado amor de la muchacha. El episodio juvenil reprimido y olvidado por la protagonista, que lo rememora recién muchos años más tarde cuando la duquesa le pregunta si alguna vez ha experimentado el amor, y el modo insidioso en que aquella ha llegado a convertirse en la marquesa de la Pivardière ponen en evidencia la imposibilidad de que prospere una atracción sincera y recíproca entre dos jóvenes inocentes en un mundo en el que priman las relaciones basadas en el interés, el cálculo, la conveniencia, el disimulo y la manipulación del otro.

Como muestra esta amplificación inicial, las modificaciones efectuadas por Hoffmann en la constelación de personajes respecto de la causa célebre mencionada como fuente, así como la nueva caracterización que hace de los que decide conservar, tienden a borrar las ambigüedades y los grises que pueden observarse en los principales caracteres

\footnotetext{
${ }^{5} \mathrm{Al}$ hacer de Charost y el marqués amigos de juventud, luego separados, Hoffmann modifica los hechos registrados en las demás elaboraciones, en las que la relación entre ambos no se entabla hasta mucho más tarde, cuando ambos se encuentran en el pequeño círculo social formado alrededor del castillo de Nerbonne, e interactúan cordialmente hasta que el recíproco entendimiento y buen trato se interrumpen una vez que el sociable anfitrión empieza a ver con recelo la afinidad del religioso hacia su esposa.
} 
PIVETTA, C.I. - Perspectivas sobre la justicia francesa del Antiguo Régimen

de aquella versión previa del affaire y a ofrecer una imagen claramente más maniquea del mundo y de los seres humanos: así, la pareja imputada judicialmente (la marquesa y su confesor Charost) es encumbrada como ejemplo de integridad moral y resistencia ante la adversidad; a estos dos outsiders incomprendidos se contraponen los dos intrigantes ya mencionados: por un lado, el caballero de Chauvelin, quien, guiado por convicciones erróneas, ejerce una influencia nefasta y destructora en su hija; por otro, el codicioso, hipócrita y materialista marqués, que la mantiene en el error con sus mentiras y embustes (tanto el engaño al que recurre para conquistarla como, una vez casados, su infidelidad, su doble vida). Para reforzar aún más el contraste entre esos personajes manipuladores o acomodaticios, que no vacilan en recurrir al fraude y la instrumentalización de sus semejantes, por un lado, y aquellos individuos anómalos, que actúan siempre guiados por la fuerza de sentimientos genuinos, por otro, Hoffmann elimina asimismo la mención al modo en que la segunda esposa del marqués convence a su marido de que, sobreponiéndose a su temor a ser condenado por el delito de bigamia, comparezca en auxilio de la marquesa acusada por su asesinato: con la supresión del loable y compasivo comportamiento de esa humilde muchacha de Auxerre hacia su "rival", Hoffmann evita que tal personaje secundario opaque a los dos inocentes injustamente perseguidos, intensificando por consiguiente el pronunciado contraste al que aspira su reconfiguración de los personajes. A su vez, este cambio condiciona otro, pues aquí el retorno del marqués para presentarse ante los tribunales recibe una explicación distinta a la que dan Gayot de Pitaval, Richer y Alexis, que lo atribuyen pura y exclusivamente a la nobleza y el buen corazón del señor de la Pivardière y, sobre todo, de su nueva esposa: ${ }^{6}$ en lugar de la preocupación altruista y desinteresada de aquel por salvar del oprobio y la muerte a su primera mujer, Hoffmann insinúa como motivo principal del regreso la egoísta especulación de un hombre perseguido por sus acreedores, que supone que lo más conveniente para él es preservar la buena relación con su esposa legítima, de la cual, al fin y al cabo, depende su subsistencia.

En resumidas cuentas, al apropiarse de este famoso affaire, Hoffmann acentúa la oposición entre apariencias (engañosas) y esencia (genuina), antítesis que proporciona la estructura básica de su Kriminalnovelle y determina los nuevos acentos que adquieren en ella los personajes, caracterizados aquí de manera netamente paroxística. Los cambios

\footnotetext{
${ }^{6}$ Richer (1783: 95-96), por ejemplo, califica la comparición espontánea del señor de la Pivardière en defensa de la inocente de una acción generosa, aunque sin el efecto deseado.
}

Pandaemonium, São Paulo, v. 22, n. 37, mai.-ago. 2019, p. 51-75 
PIVETTA, C.I. - Perspectivas sobre la justicia francesa del Antiguo Résimen

efectuados refuerzan su denuncia de una sociedad en la cual los valores están invertidos: mientras que los inocentes y virtuosos son tratados como criminales y solo pueden ocupar un lugar de marginalidad en ese mundo degradado que los hostiga y persigue, ${ }^{7}$ prosperan los intrigantes y los impostores, esas almas oscuras movidas por las intenciones más deleznables e inconfesables. El insólito "procès d'assasinat d'un homme vivant" en el que un juez persigue a un "mort imaginaire" (1735: 24), tal como denomina el caso en 1735 el primero en convertirlo en una causa célebre, ${ }^{8}$ es muy apto para mostrar la opacidad de un mundo donde nada es lo que parece; y tal es sin duda uno de los principales atractivos que tiene la historia de la Pivardière para el escritor de Bamberg. Por eso en su reescritura, los hechos -que ni para Gayot de Pitaval ni para Richer constituían una materia de controversias o incertidumbre- se vuelven problemáticos. No solo se los narra varias veces desde distintos puntos de vista, confrontando así múltiples versiones, muchas veces contradictorias, sobre lo sucedido la noche del supuesto crimen, sino que además, el modo en que se dan a conocer tales versiones parciales y discordantes induce deliberadamente a error, pues primero se narran las versiones falaces y recién en las últimas páginas se aclara cómo sucedieron en realidad las cosas. Así, el lector es inducido a dejarse llevar por las falsas apariencias, con lo cual experimenta por sí mismo el carácter engañoso de la realidad. El mismo efecto persigue el marco que Hoffmann añade a su Novelle, en el cual los aristócratas reunidos en torno a la duquesa comentan los dos conyuguicidios ya mencionados, el cometido en los bosques de Boulogne y el que el conde de Saint-Hermine atribuye a la marquesa de la Pivardière. Puesto que allí no se dan pistas para sospechar que la noticia transmitida por el conde es apócrifa, tanto el auditorio ficticio del marco como el lector la dan por cierta y solo posteriormente caen en la cuenta de su error. Así, la narración avanza explicando de un modo deliberadamente lento aquello que al comienzo aparece como una evidencia incuestionada. Lo mismo ocurre en el marco inicial y final con la caracterización del conde de Saint-Hermine: este personaje que primero lamenta la pérdida del marqués y oficial de su escuadrón como la de un hombre valiente y honrado, al final, al enterarse de que este sigue vivo, se rectifica diciendo que se trata en realidad de "ein großer Taugenichts" (1985: 764), merecedor de

\footnotetext{
${ }^{7}$ No es casual que Hoffmann omita mencionar la larga sobrevida del prior, que, una vez absuelto, vive muchos años más en su abadía, tal como constata Richer; silenciando el destino ulterior de este longevo personaje, vuelve a acentuar la impresión de que en este mundo no hay lugar ni ventura posible para los inocentes perseguidos.

${ }^{8}$ La alusión de Gayot de Pitaval al enfermo de la comedia de Molière deja entrever una cuota de humor, que desaparece por completo en la sombría versión de Hoffmann.
}

Pandaemonium, São Paulo, v. 22, n. 37, mai.-ago. 2019, p. 51-75 
PIVETTA, C.I. - Perspectivas sobre la justicia francesa del Antiguo Régimen

un justo castigo. La inconsecuente y ligera opinión del conde es equiparada allí a la de la veleidosas masas parisinas, que primero sucumben a los indicios falaces que acusan a la marquesa y más tarde se muestran totalmente convencidas de su inocencia. Con ello Hoffmann deja entrever que ni el pueblo ni los miembros de la distinguida sociedad nucleada alrededor de la duquesa d'Aiguillon son ajenos a la hipocresía y la degradación moral imperantes, pues se dejan convencer por las falsas apariencias y las mentiras deslumbrantes. El hecho de que recién en las últimas líneas el narrador revele una faceta antes pasada por alto del conde, que ya no parece un informante tan confiable como al inicio, ejemplifica una vez más este recurso que consiste en retardar las explicaciones que permiten al lector ver claro y captar la verdad de los hechos.

\section{Alexis: ¿la recuperación de los hechos tal cual fueron?}

Pasemos ahora a la segunda versión decimonónica a considerar, menos conocida, por lo que nos referiremos muy brevemente a su autor y a la colección en la cual se edita. Willibald Alexis es el seudónimo de Georg Wilhelm Heinrich Häring (1798-1871), escritor y publicista silesiano que a los 26 años abandona la carrera como jurista a la que parecían destinarlo sus estudios de Derecho para dedicarse de manera exclusiva a la escritura, tras el éxito que cosecha con su ópera prima, la novela histórica Walladmor (1824), que aparece sin su firma, como traducción de un original de W. Scott; a partir de entonces el escritor, que se instala desde 1806 en Berlín, edita varias novelas sobre la historia de Prusia ${ }^{9}$ y a partir de 1842, junto con Julius Eduard Hitzig, la exitosa colección Der neue Pitaval, en cuyo cuarto tomo aparece un año después "Der Herr von Pivardiere". En este proyecto editorial emprendido a pedido de la editorial Brockhaus, Alexis y Hitzig se proponen proseguir y ampliar la tarea iniciada más de un siglo antes por el lionés Gayot de Pitaval, incluyendo casos de épocas y latitudes variadas, tal como promete el subtítulo de esta "Sammlung der interessantesten Criminalgeschichten aller Länder aus älterer und neuerer Zeit". El homenaje al pionero cuyo apellido figura a la cabeza de la obra no implica que los nuevos coleccionistas no tengan divergencias con él. De hecho en un prólogo de 1842 firmado por Hitzig y Alexis, estos enumeran sus críticas a la obra del precursor: más allá de que ven como una limitación el hecho de que este haya recopilado

\footnotetext{
${ }^{9}$ Como novelista histórico, sigue el modelo de W. Scott, mostrando los vínculos entre la historia y la vida de los hombres comunes.
}

Pandaemonium, São Paulo, v. 22, n. 37, mai.-ago. 2019, p. 51-75 
PIVETTA, C.I. - Perspectivas sobre la justicia francesa del Antiguo Régimen

mayoritariamente causas de su propia nación, le reprochan, haciendo suyos argumentos de Richer, la falta de claridad y orden en la exposición, las numerosas y largas digresiones sobre asuntos que poco tienen que ver con los casos tratados y la "unleidliche Schwatzhaftigkeit" (Alexis/ Hitzig, 1842, vol. 1: XIV) con la que repone los fundamentos jurídicos que hace falta conocer para entender las causas, todo lo cual hace que el lector se vea obligado a adivinar con gran dificultad lo sucedido. Otros defectos - de los que a su entender adolece asimismo la colección de Richer- son la sobrevaloración de la actuación de los abogados que intervienen en los procesos y el lugar privilegiado que ocupa en las causas célebres el examen de los alegatos y de la destreza retórica de aquellos letrados.

Para subsanar estos problemas y devolver actualidad a las viejas causas compiladas por Gayot de Pitaval y Richer, en lugar de concentrarse en sus aspectos jurídicos, los editores de este compendio alemán se proponen "der Tatsache ihr Vorrecht $\mathrm{zu}$ vindiciren und die Advokatenvorträge in die ihnen gebührenden Schranken zurückzuverweisen" (ibíd.: XVI). La voluntad de alcanzar la mayor objetividad posible se reitera en los paratextos a este y otros volúmenes de Der neue Pitaval; así, cuando aseguran que "die Aufgabe dieses Werkes" consiste en ofrecer "eine klar fortlaufende Erzählung des Thatsächlichen" (ibíd.: XXI) o cuando afirman:

Wir haben [...] unsere Aufgabe gelöst, wenn wir nach besten Kräften das Factische aus
dem Wust und der Voreingenommenheit älterer Berichterstatter reinigten und die That in
ihrer Lebendigkeit und ihren psychologischen Motiven rein und anschaulich für sich
selbst sprechen ließen. [...] Unser Verdienst genügt uns, das Historische und allgemein
Menschliche Jedem verständlich dargestellt und die Unparteilichkeit, welche eines
Richters erste Pflicht ist, geübt zu haben (1843, vol. 3: XI).

Gracias a esta perseguida imparcialidad, la nueva colección procura distinguirse no solo de las anticuadas recopilaciones de causas célebres, en las cuales los hechos se pierden detrás de embrolladas disquisiciones jurídicas o digresiones sin fin, sino asimismo de las reelaboraciones literarias que ciertos escritores contemporáneos hacen de muchas de esas viejas causas, apartándose de lo corroborado por sus fuentes e introduciendo variaciones producto de su propia imaginación. A diferencia de ellos, Alexis no solo prescinde de introducir alteraciones o amplificaciones ficticias, sino que casi los únicos comentarios que se permite añadir son indicaciones, por lo general escuetas, de las lagunas, inconsistencias o posibles errores detectados en las fuentes consultadas. Pero más allá de las declaraciones programáticas y la exposición de 
PIVETTA, C.I. - Perspectivas sobre la justicia francesa del Antiguo Régimen

intenciones formuladas en los prólogos, veamos cómo procede el escritor al reelaborar el caso puntual que nos interesa.

Como preanuncia el título, que devuelve su protagonismo a Der Herr von Pivardiere, este buen conocedor de la tradición de las causas célebres, también se basa para su reescritura en la elaboración de Richer, con menos variaciones que Hoffmann: en efecto, conserva, con escasos cambios y pocos agregados significativos, el orden general en el que este expone tanto lo ocurrido como los planteos jurídicos de las diversas partes, de acuerdo con lo argumentado por los abogados. También mantiene las interpretaciones -casi siempre laudatorias- que Richer hace de los fallos judiciales, ${ }^{10}$ así como sus explicaciones de la conducta de los involucrados en el caso, con lo cual no se producen cambios sustanciales en el perfil que tienen los personajes de este hipotexto.

Ilustrativo a propósito de este último aspecto es examinar la caracterización del señor de la Pivardière, que contrasta con la que encontramos en la novela corta de Hoffmann. Mientras que este último autor, al hacer del marqués un traidor de su amigo de juventud Charost y un embustero que seduce mediante simulaciones a la señorita de Chauvelin, lo convierte en un hipócrita, en un impostor por antonomasia, acentuando unilateralmente los defectos del personaje esbozados en las versiones precedentes, el autor de Der neue Pitaval lo retrata con pinceladas mucho más benévolas: por más que al final califica de "unverzeilich" (1843: 393) el modo en que se comporta con su primera esposa, en varias apreciaciones previas se percibe una mirada comprensiva hacia ese marido ciertamente influenciable y dominado por el qué dirán y el temor al ridículo (teme pasar por celoso y por cornudo), que, sin embargo, no vacila en acudir cuando su mujer está en apuros. Ya Gayot de Pitaval, al referir las circunstancias que desembocan en el nuevo matrimonio de este personaje, se afana en disculpar al bígamo: por un lado, resalta las virtudes de la nueva esposa, con lo cual justifica al hombre que, pese a ser casado, ha cedido a los innumerables encantos y la prudencia de la muchacha; por otro, atribuye la decisión del señor de la Pivardière de contraer matrimonio nuevamente a un sentimiento

\footnotetext{
${ }^{10}$ Véase por ejemplo la siguiente afirmación: "diese Betrachtungen sind eine Apologie des Arrets, die durch die requète civile angefochten wurde" (1783: 114). Pese a que al final Richer reconoce abiertamente las irregularidades de la instrucción debidas a la mala fe de los primeros jueces (Bonnet y Morin, quienes, movidos por sed de venganza y por una hostilidad de larga data contra la familia del prior Charost, incurren en el delito de prevaricación, con la complicidad de sus subalternos), por lo general justifica el proceder de los magistrados. Así opina, por ejemplo, que en esta causa el peligro de errar es grande, puesto que hay pruebas parejas de ambas partes (ibíd.: 113-115), y alaba la sabiduría y la conformidad con la ley de los dos fallos que quedan sin efecto al ser anulados por recursos interpuestos por los acusados (ibíd.: 94 y 114). En esto Richer no innova, sino que sigue a su predecesor Gayot de Pitaval, cuya obra también justifica en última instancia las decisiones tomadas por los tribunales y cortes franceses.
} 
PIVETTA, C.I. - Perspectivas sobre la justicia francesa del Antiguo Régimen

genuino, ya que este, al asumir el puesto de ujier heredado del difunto padre de su nueva esposa, acepta una posición social mucho más desventajosa que la que tiene previamente como oficial del rey, con lo cual demuestra que los honores externos le son indiferentes; su actitud empática hacia este personaje se plasma en la siguiente sentencia con la que Gayot de Pitaval remata el relato de ese episodio: 'L'amour fait bien des métamorphoses plus étranges" (1735: 6). Así pues, Alexis no innova al destacar rasgos positivos del mentado en el título de su versión, sino que permanece en la estela de Richer, quien a su vez sigue de cerca a Gayot de Pitaval. La observación, aparentemente insignificante, que aquel retoma de Richer según la cual el otrora oficial de dragones cumple "mit Treue und Geschicklichkeit" (1843: 368) con las obligaciones derivadas del cargo subalterno que ocupa en Auxerre contiene implícita una mitigación de la culpa del marido infiel, en la medida en que contribuye a mostrar su segundo matrimonio no como consecuencia de una pasión caprichosa o efímera, sino como fruto de un afecto auténtico, sólido y duradero (sentimiento que es absolutamente incapaz de experimentar la figura equivalente de la narración de Hoffmann).

La diferencia más notoria con respecto a la causa célebre de Richer es la notable concisión alcanzada por el editor de Der neue Pitaval, quien reduce o suprime tanto las referencias a los códigos y leyes que rigen el derecho penal francés como las numerosas aclaraciones sobre el derecho procesal del Ancien Régime añadidas por aquel jurisconsulto para hacer comprensibles los complejos recursos legales de este enrevesado caso y esclarecer así lo que Gayot de Pitaval explicaba -cuando lo hacía-de manera a su entender demasiado somera y elemental, cuando no deficiente o poco seria. ${ }^{11}$ Tales recortes se justifican porque es necesario actualizar la vieja historia, adaptándola al público contemporáneo, al que ya no le interesa conocer los pormenores de cómo funciona el aparato judicial francés de un pasado lejano:

Für unsern Leser wird es, meinen wir, von mehr Interese sein, statt ihnen dieses Bild der Unvollkommenheiten des damaligen Proceßverfahrens zu detaillieren, wenn wir sie schneller zur Entwicklung dieses allerdings sonderbarsten aller verwickelten Criminalprocesse führen (ibíd.: 385).

\footnotetext{
${ }^{11}$ Por ejemplo, Alexis condensa en unas líneas los fundamentos que aducen los imputados para recusar a los primeros jueces en investigar el supuesto asesinato, en lugar de detallarlos uno a uno, como hace Richer, que dedica a ello cerca de veinte páginas (en la edición consignada, de la 72 a la 90); asimismo aquel recorta la consideración pormenorizada de muchos aspectos legales controvertidos, entre otros el examen de las pruebas y documentos presentados por las partes en litigio, como aquellos documentos presentados por el defensor de la señora de la Pivardière para probar que su esposo está vivo.
} 
PIVETTA, C.I. - Perspectivas sobre la justicia francesa del Antiguo Régimen

Si bien, como afirma Alexis aquí, no es su intención dar una imagen acabada y prolija de todas las imperfecciones del procedimiento vigente en la Francia del siglo XVII, muchas de las reflexiones que suscita este insólito caso están dedicadas ciertamente a resaltar lo absurdo de las situaciones procesales a las que conduce la aplicación de la ordenanza francesa de 1670: así, por ejemplo, opina que este proceso se enreda "[dreht] in den Formalitäten des damaligen Rechtsverfahren" (ibíd.: 383), que "der höchste Ernst der Sache" (ibíd.) se ve gravemente menoscabada cuando la dilucidación de si se produjo o no un asesinato queda subsumida a cuestiones de competencia de los diversos tribunales que intervienen, o expresa reiterademente sus reparos ante el avance demorado y tortuoso de ese "Knäuel von Processen" que se acumulan "zur Freude der Advokaten” (ibíd.: 384). Ahora bien, aunque Alexis no omite ninguna de las instancias por las que pasan los numerosos juicios que desencadena el caso la Pivardière, y recapitula con fidelidad todas las facetas jurídicas relevantes reseñadas en las causas célebres preexistentes, no es este el aspecto que privilegia en su reescritura. Como ya hemos observado, describe esas innumerables idas y vueltas de los litigios, que atribuye al formalismo excesivo de la legislación francesa, de manera mucho más sucinta que sus predecesores. Y esto porque más que las discusiones técnicas o el cuestionamiento del antiguo procedimiento criminal francés le interesa la dimensión histórica del caso, así como la psicológica.

De ahí su distanciamiento expreso de Gayot de Pitaval ("Pitaval schwelgt, als pariser Parlamentsadvocat, in Darlegung der gewandten Fechterstreiche, mit denen die Parteien sich begegneten”, ibíd.: 385) y su mayor afinidad con Richer, quien en su afán por distinguirse de su precedesor, cuyo estilo farragoso y confuso critica, introduce profundos cambios, que en su mayoría son conservados en Der neue Pitaval: no solo dota su narración de un nuevo orden, mucho más claro y explícito, ${ }^{12}$ sino que además suma mucha información inédita sobre los caracteres y la época, con lo cual da un mayor espesor psicológico a las figuras centrales y una densidad nueva al trasfondo histórico en el que se inserta esta historia privada. La mayor parte de las descripciones y anécdotas que incorpora con este último propósito son retomadas por Alexis casi al pie de la letra: entre otras, la aclaración inicial sobre sobre los compromisos derivados del vasallaje al

\footnotetext{
${ }^{12}$ Richer comienza con los argumentos y pruebas a favor del asesinato, luego recopila aquellos en contra, y concluye con la revelación de la falsedad de los principales testimonios acusatorios, secuencia que le permite dejar hasta último momento al lector en vilo sobre el fallo definitivo e introducir así una suerte de suspenso acerca del desenlace del affaire.
}

Pandaemonium, São Paulo, v. 22, n. 37, mai.-ago. 2019, p. 51-75 
PIVETTA, C.I. - Perspectivas sobre la justicia francesa del Antiguo Régimen

que está sometido el señor de la Pivardière en tanto súbdito de Luis XIV ${ }^{13}$ la descripción de la animada vida social en la pequeña localidad de Nerbonne, en la cual participan también los clérigos como Charost; el episodio en el que se narra la intercesión de la esposa de Auxerre ante el rey para conseguir una lettre d'état ${ }^{14}$ para su marido; también la observación acerca de la dificultad para determinar a quién le incumbe ejercer la autoridad legal sobre Nerbonne, que pinta un momento histórico en el cual la jurisdicción sobre algunos parajes pequeños aún no está establecida con claridad y es objeto frecuente de controversias. Acentuando entonces una tendencia que ya se vislumbra en Richer, en Der Herr von Pivardiere la narración histórica gana terreno sobre la historia del derrotero de los procesos judiciales.

En una declaración un par de años posterior al relato analizado aquí, en la que Alexis se explaya precisando justamente cómo concibe la "tarea histórica" que se ha propuesto llevar a cabo en Der neue Pitaval, justifica así su interés por el crimen en tanto testimonio de un determinado momento histórico:

So ist unsere Aufgabe eine historische, und war es schon, ehe wir uns entschlossen, den interessanteren Fällen aus dem Privatleben die großen Criminalprocesse aus dem öffentlichen und Staatsleben anzureihen. [...] In all den grauenvollen Verbrechen, welche der Volkswahn in gewissen Zeitepochen hervorrief, ist die einzelne That, der eigentliche Gegenstand des Processes, in der Regel unbedeutend. Eine nur actenmäßige Darstellung des Thatsächlichen würde zur dürren unverständlichen Skizze werden; vielleicht ein Beitrag mehr zu den Ungerechtigkeiten, zu dem unschuldig vergossenen Blute, das von allen Richterstühlen träuft, denen, wo im Namen Gottes, des Königs oder des Volkes, gerichtet wurde. Aber die einzelne Handlung, Verbrechen und Strafen, als Glied eines organischen Ganzen, einer gewaltigen Bewegung, einer furchtbaren Strömung im großen Lebensprocesse der Völker gedacht, gibt die Abrundung, die Abgeschlossenheit, die der Jurist von jedem Falle mit Recht fodert, aber mit Unrecht in zu engen Grenzen sucht (1845, vol, 7: XII-XIII).

Para el editor de esta colección, entonces, no importa "die einzelne That, der eigentliche Gegenstand des Processes”, sino el crimen “als Glied eines organischen Ganzen, einer gewaltigen Bewegung, einer furchtbaren Strömung im großen Lebensprocesse der Völker". La tarea que asume aquí Alexis supone -tal como ha señalado Joachim Linder en su lúcido análisis de este extracto del prólogo al séptimo tomo de la colección- dar un cierre definitivo a los casos de otras épocas (de ahí la

\footnotetext{
${ }^{13}$ La situación del protagonista es la de muchos señores de la época que cuentan con fortunas módicas, con las que no pueden costearse los gastos de traslados y armas para asumir el compromiso de defender militarmente al rey.

${ }^{14}$ Como aclara Richer y repite Alexis, este documento exime por un cierto tiempo a su portador de enfrentar cualquier demanda legal, y en el caso del señor de la Pivardière funciona como un salvoconducto para que pueda acudir a demostrar que sigue vivo sin que puedan prosperar eventuales demandas de sus acreedores ni que se lo juzgue por bigamia.
} 
PIVETTA, C.I. - Perspectivas sobre la justicia francesa del Antiguo Régimen

insistencia en la Abrundung, la Abgeschlossenheit) explicando el delito a partir de la situación histórica en la que se inserta, aunque interpretándolo "aus eigener Wertperspektive" (LINDER 1982: 57). La reconsideración de crímenes pretéritos desde la distancia que da el tiempo transcurrido permitiría, según pretende el escritor y prologuista, poner ese pasado en perspectiva para recuperar la objetividad y superar las limitaciones debidas a los excesos del momento en que se produce el delito (Volkswahn), formándose un juicio no sesgado sobre lo sucedido. Ahora bien, dado que -como observa con acierto aquel crítico- el modo de redondear y clausurar el caso consiste en vincular crimen y pena en "eine Anfang-Ende-Verbindung" (ibíd.: 91), la reescritura, presuntamente imparcial, de esos viejos affaires termina en realidad revalidando la sanción impuesta en su momento a los autores del delito; además, si en esta colección concebida para un público amplio las discusiones jurídicas son secundarias, es porque de lo que se trata es de que cualquiera, incluso quien nada sabe de Derecho, pueda suscribir convencido el veredicto ya emitido, ratificando así la perspectiva estatal y punitiva desde la cual se vuelven a narrar los hechos. ${ }^{15}$

En las antípodas del propósito que subyace a la reescritura hoffmaniana del caso en cuestión de poner de manifiesto el carácter confuso y opaco de la realidad, la objetividad que Alexis promete restablecer en Der Herr von Pivardiere, purgando la historia de las "falsedades" que se han ido colando en ella con el correr de los años y de las adaptaciones, supone que los hechos pueden ser contados tal como efectivamente ocurrieron. Aunque en ciertos pasajes el narrador confronta al lector con sucesos que es imposible esclarecer con total certeza, con ello no hace más que reforzar la impresión de que todo el resto es cierto. Así, cuando en el desenlace aquel observa que no tiene suficiente información para contar qué fue de los jueces de Châtillon-sur-Indre que dictan a sabiendas una resolución injusta contra los dos inocentes, no se avergüenza de exponer su ignorancia a ojos de sus lectores; al contrario, pues con su actitud recelosa a opinar sobre lo que desconoce, a dar por cierto lo ignorado, prueba una vez más que bajo ningún aspecto apelará a la invención para colmar esas incertidumbres, para saciar la lógica curiosidad de quien haya leído hasta allí por saber si estos prevaricadores fueron debidamente juzgados y castigados. De este modo, el narrador se reviste de la autoridad

\footnotetext{
${ }^{15}$ Linder (1982: 91) subraya que en las primeras dos series de Der neue Pitaval (1842-1856) domina "die vergeltungsorientierte Legitimation staatlichen Strafens" y concluye que "Hieraus ergibt sich dann der Eindruck, das Verbrechen sei ein im Menschen beschlossener und auch (mit der Hinrichtung!) abgeschlossener Vorgang, der im wesentlichen aber schicksalhaft entsteht" (ibíd.).
}

Pandaemonium, São Paulo, v. 22, n. 37, mai.-ago. 2019, p. 51-75 
PIVETTA, C.I. - Perspectivas sobre la justicia francesa del Antiguo Régimen

de un cronista fidedigno de lo acaecido en el pasado, de un informante que no está dispuesto a alejarse un ápice de lo fehacientemente constatado; por eso también pone constantemente a prueba la verdad de lo transmitido: señala todo aquello que considera incierto y explica por qué los testimonios y pruebas tanto del asesinato como de la pervivencia del señor de La Pivardière le parecen igualmente novelescos (1843: 367). ${ }^{16}$ Ahora bien, indudablemente toda versión de esta historia -o de cualquier otra- implica una cierta interpretación del "proceso vital de los pueblos" del cual los episodios narrados dan testimonio; en la medida en que Alexis pretende ofrecer una versión fiel e imparcial de lo sucedido, naturaliza su propia visión lugar y momento en que ocurren los hechos narrados. En la última parte de este trabajo estudiaremos cómo interpreta y redondea el pretendido cronista objetivo de Der neue Pitaval el caso la Pivardière, comparándolo con otro caso de la misma colección también ocurrido en la Francia de fines del siglo XVII. Indagar de qué modo y con qué intención reconstruye Alexis ese pasado nos permitirá luego establecer un contraste con la reconstrucción de ese mismo contexto histórico que realiza Hoffmann en su novela corta.

\section{Ayer y hoy: ¿continuidad o ruptura?}

En el prólogo al segundo tomo de Der neue Pitaval se lee la siguiente declaración: "Daß wir unbedingt die Geschworenengerichte in Frankreich für einen Fortschritt halten in Vergleich zur Criminaljustiz der alten Parlamente, wird zur Genüge aus den in den künftigen Bänden aufzunehmenden Fällen aus dem ältern Pitaval hervorgehen" (1842: XVI). El pasaje requiere una contextualización de las circunstancias en las que se edita ese volumen del compendio, justamente en medio de un debate acerca de la abolición del procedimiento inquisitorial, aún vigente en buena parte del territorio prusiano (con excepción de la Prusia renana, en la cual, por haber estado bajo dominio napoleónico entre 1794 y 1815, ya ha tenido lugar una importante reforma). Lo que está en discusión en la Prusia de la década de 1840 es la sustitución de aquellos procesos en los que el imputado es juzgado por magistrados profesionales en base a una instrucción que se

\footnotetext{
${ }^{16}$ Por ejemplo, cree improbable que para matar a un solo hombre dormido hayan sido necesarias cinco personas (el prior, dos de sus sirvientes, la señora de la Pivardière y su criada Marguerite Mercier) y pone en entredicho el argumento según el cual la noche del crimen la señora manda a Katherine Lemoine a buscar huevos a una alejada granja para ofrecer algo de comer a los hambrientos sirvientes del prior, pues a su entender no es compatible con el banquete que ha tenido lugar ese mismo día, después del cual debería haber sobrado comida que hiciera innecesaria tal excursión nocturna (1843: 361).
} 
PIVETTA, C.I. - Perspectivas sobre la justicia francesa del Antiguo Régimen

desarrolla fundamentalmente en forma escrita, ${ }^{17} \mathrm{y}$ su reemplazo por juicios orales y públicos en los que la decisión es tomada por un jurado integrado por ciudadanos sin una formación jurídica específica. Alexis no se identifica ni con los defensores ni con los detractores acérrimos de la reforma del sistema vigente (propulsada por un proyecto de ley de 1843), sino que adopta una posición moderada, ya que en su opinión "keine Procedurform die Vergießung unschuldigen Blutes gänzlich verhindern könne” (ibíd.: XVII). Pero volvamos por un momento a la cita inicial: en ella sostiene que en Francia la implementación de tribunales constituidos por jurados (implementación violenta, pues fue fruto de la Revolución, aunque el prologuista omite allí mencionarlo) constituyó un indudable progreso; prueba de ello son los viejos casos franceses, reelaboraciones de causas ya tratadas por Gayot de Pitaval, que el escritor tiene previsto incorporar a los futuros tomos de su colección, casos en los cuales quedan a la vista las flagrantes arbitrariedades de lo que llama la "Criminaljustiz der alten Parlamente" (cf. supra). Lo que a sus ojos se deriva con una evidencia contundente de la consideración esos antiguos crímenes de la nación vecina y el modo en que estos han sido dirimidos ante la ley, a saber, el carácter altamente reprobable de lo que se conoce como proceso inquisitorial (Inquisitionsverfahren), no da lugar, sin embargo, a una condena igualmente radical de este procedimiento aún vigente en su patria. El escritor se muestra aquí reacio a reconocer las afinidades existentes entre el procedimiento criminal usado en Francia durante el Ancien Régime y el que rige aún en gran parte de la Prusia de la Restauración, por más que en esta última todavía el carácter escrito de la instrucción y la falta de publicidad de los procesos afecten seriamente las posibilidades de defensa del acusado, quien solo accede a las actas una vez que el juicio ha concluido.

La reticencia del prologuista, autor y editor de Der neue Pitaval a tomar posición en los debates jurídicos contemporáneos está en sintonía con el predominio de casos históricos y extranjeros en las dos primeras series de esta colección (esto es, hasta el vol. 24, aparecido en 1856). ${ }^{18}$ Claro que, por sí solo, este último dato no implica necesariamente una tendencia conservadora o una actitud evasiva a sentar posición en los

\footnotetext{
${ }^{17}$ El procedimiento vigente por entonces en Prusia consiste en que las partes presenten ante el juez de instrucción los elementos de cargo y descargo, integrados por este en un informe escrito que se eleva a otro magistrado encargado de pronunciar la sentencia en base a ese dossier.

${ }^{18}$ La primera serie está formada por los primeros doce volúmenes (1842-47) y la segunda va desde el décimo tercero hasta el vigésimo cuarto (1848-56); estas dos series abarcan casi todo el período en que Alexis es responsable de la colección, pues en la década del 60 deja de escribir por problemas de salud, con lo cual es reemplazado por Anton Vollert, quien continúa la labor hasta 1890 (vol. 60).
} 
PIVETTA, C.I. - Perspectivas sobre la justicia francesa del Antiguo Régimen

asuntos de actualidad, y hay que examinar el tratamiento que reciben las causas de otras épocas y latitudes en esa obra que se quiere dedicada a la actualidad, ${ }^{19}$ a fin de desentrañar cómo concibe su autor la relación entre la realidad ajena y la propia, entre pasado y presente.

Para eso veamos en primer lugar uno de los pasajes del caso La Pivardière en los que el narrador abandona por un momento el tono del cronista neutral de los hechos y deja oír una valoración personal:

Die Communicationen der überdies unter sich eiferfüchtigen Gerichte fanden nicht mit der Schnelligkeit von heute statt. Es konnte von einem Gerichte schon etwas ermittelt und entschieden sein, wo ein anderes sich nachher befugt hielt, erst die Untersuchung einzuleiten. [...] Nun trat das sonderbarste Verhältniß ein, was in heutigen Verhältnissen, wo die Zeitungen die Vermittler der Gedanken und Nachrichten sind, undenkbar wäre und sich nur durch die Verhältnisse eines großen Landes wie Frankreich erklären läßt, wo es noch viele Berechtigte gibt, aber die Idee der Staatseinheit noch nicht vollständig ins Leben gedrungen ist (1843: 366).

La crítica de las comunicaciones lentas e ineficientes entre los distintos tribunales que administran justicia en la Francia del siglo XVII le permite establecer un contrapunto con el presente de la enunciación, en el cual algo semejante sería, en sus propias palabras, “impensable". La última oración de la cita anterior, que destaca el papel que cumplen "en las circunstancias actuales" los periódicos en tanto medios de difusión de "pensamientos y noticias", está imbuida de optimismo respecto de las posibilidades que brinda la técnica para la veloz circulación de la información y por ende -tal parece ser el corolario implícito- para un adecuado funcionamiento de las diversas instancias judiciales que eventualmente pueden definir un proceso. Pero el contraste no solo se establece en el plano temporal, sino igualmente en el geográfico. Un poco antes se lee por ejemplo que "Vor unsern Gerichten würde die Aussage des siebzehnjährigen Mädchens [...] einige Bedenken erregt haben" (ibíd.: 360); la frase sugiere que en el marco del sistema judicial prusiano sería inaceptable una declaración tan poco sólida como la que presta la joven criada Marguerite Mercier, con lo cual parece sugerirse que si el mismo caso se hubiera

\footnotetext{
${ }^{19}$ Uno de los pocos estudiosos en ensayar un abordaje conjunto de la voluminosa colección de Alexis y Hitzig ha señalado que, a pesar de que los editores de Der neue Pitaval, al aparecer la primera edición, afirman que se trata de una obra abocada a la actualidad (1842, vol. I: XVIII), en realidad, si se consideran uno a uno los casos incluidos en las primeras dos series, en ellas prima la orientación histórica por sobre los casos actuales; el crítico agrega que esta tendencia conduce " $\mathrm{zu}$ einem sehr statischen Bild von den Normen des Stafrechts und vom Verbrecher. Die Bände des Neuen Pitaval, blickt man nun einmal auf die erste oder die ersten beiden Folgen, vermitteln den Anschein, als würden sich das Verbrechen, der verbrecherische Mensch und die grundlegenden Normen des Strafrechts nie ändern, lediglich das Strafverfahren würde humaner einerseits und effektiver andererseits" (LINDER, 1982: 90), lo cual se confirma también en el análisis de los dos casos que proponemos a continuación.
}

Pandaemonium, São Paulo, v. 22, n. 37, mai.-ago. 2019, p. 51-75 
PIVETTA, C.I. - Perspectivas sobre la justicia francesa del Antiguo Régimen

planteado ante tribunales alemanes seguramente no habría sido resuelto de un modo tan objetable. Antes de sacar conclusiones sobre el vínculo esbozado aquí entre esas dos épocas y naciones, examinemos un ejemplo más, tomado de otra de las causas tratada primero por Gayot de Pitaval y reescrita luego por Alexis que también está ambientada en la Francia de la segunda mitad del siglo XVII.

Nos referimos a la historia de la marquesa de Gange (Der neue Pitaval, vol. 2, 1842), en la cual Alexis postula un contraste similar entre el pasado evocado y la actualidad desde la cual se lo evoca. Allí se lee a propósito del abate de Gange, principal autor intelectual y material del cruel asesinato de aquella bella y virtuosa dama: "Er war boshaft, voll Tücke, rachsüchtig und herrschsüchtig, und im Innern roh und wild bis zu einem Grade, wie er beim heutigen Culturzustande kaum zu den Möglichkeiten gehört" (ibíd.: 421; el subrayado es nuestro). Y más adelante también:

Klar ist ferner der Charakter des Abbé, insofern die Geschichte wahr berichtet, wo sie uns solche raffinirte und vollkommene Bösewichter vorführt, wie Humanität oder Mattigkeit sie unter den gegenwärtigen Generationen nicht mehr aufkommen lassen (ibíd.: 445; el subrayado es nuestro).

Si el extracto antes comentado de Der Herr von Pivardiere rezuma una actitud confiada respecto de los avances de la técnica y sus potenciales beneficios en el ámbito de la administración de la justicia, estas dos últimas citas dan por sobreentendido que para el silesiano la cultura tiene efectos positivos que impedirían que pueda surgir en el siglo XIX un ser tan depravado e inescrupuloso como aquel pérfido abate que, adoptando ante el mundo todas las apariencias de un hombre cortés, culto y correcto, trama secretamente un sinnúmero de intrigas para quedarse con la herencia de la mujer de su hermano y al mismo tiempo torturarla por no haber cedido a sus reiterados intentos de seducción. Así, pues, la historia de la casta dama hostigada y finalmente asesinada por su codicioso y vengativo cuñado con la probable complicidad del marido de aquella y del tercer hermano de Gange, un manipulable caballero, es presentada como "ein Schreckensbild aus den letzten Tagen der Feudalgewalt unter der französischen Seigneurie” (ibíd.: 415), en nítido contraste con el presente desde el que Alexis escribe, en el cual -según sugieren valoraciones como las citadas, que el narrador intercala discretamente en la narración de los hechos- el elevado grado de desarrollo cultural ha permitido erradicar tales personalidades criminales.

A pesar de que el proceso judicial desencadenado por este cruel asesinato no reviste ningún interés especial desde el punto de vista jurídico, la reescritura de ese caso 
PIVETTA, C.I. - Perspectivas sobre la justicia francesa del Antiguo Régimen

particular se justifica porque en él se plasman rasgos generales de la época en que se produce, un tiempo en el cual prospera la omnipotencia de señores feudales como los hermanos de Gange, ${ }^{20}$ es decir, por su valor histórico. De manera que si en Der neue Pitaval encuentran cabida affaires carentes de interés para juristas y especialistas es porque allí los casos interesan principalmente en tanto "Symbole verirrter Zeitrichtungen" (1844, vol. 6: VII). Así hay que entender justamente los affaires del señor de la Pivardière y de la marquesa de Gange, al igual que muchos otros que recrean la misma época: ${ }^{21}$ como símbolos de una época desencaminada que afortunadamente ha quedado atrás. Hemos comprobado antes, a partir del análisis de las intervenciones del narrador que confrontan la Francia prerrevolucionaria con un aquí y ahora mostrado por contraste como un estadio superior de la evolución histórica, cómo el cuadro del Ancien Régime trazado en esas dos narraciones supone una exaltación tácita del presente prusiano desde el que Alexis mira atrás. Así, la inclusión de estos crímenes extranjeros del siglo XVII en la colección alemana que comienza a editarse en 1842 viene a probar que a la larga se impone lo que en otra parte su autor llama "die Gerechtigkeit der Geschichte" (1843, vol. 3: VIII). El modo en que el escritor reelabora ambas causas en Der neue Pitaval lejos de incitar al lector a reconocer los ecos actuales de los aspectos cuestionados en la justicia penal de otras épocas, tiende a disociar la imagen del pasado evocado mostrado como ajeno, lejano y superado- respecto de la realidad propia contemporánea, con lo cual este "intellectuel du "juste milieu" (CARPENT 2002) transmite una visión tranquilizadora y conservadora de la relación entre ayer y hoy.

Mientras que Alexis no admite ninguna continuidad entre la cuestionable situación jurídica del Antiguo Régimen y su propia época, sino todo lo contrario, el modo en que Hoffmann trata el caso de la Pivardière habilita una reflexión sobre ciertas pervivencias o resabios, en su propio presente, de aquel pasado aparentemente superado y abolido. Por eso su versión ilumina las afinidades entre ambos momentos históricos. Al igual que Alexis, también él deja de lado la mayor parte de las embrolladas cuestiones jurídicas suscitadas por el caso en las que se demora Richer, pero su reducción de la descripción pormenorizada de los litigios es más selectiva, apunta a algo más que a agilizar la lectura suprimiendo las largas explicaciones sobre los complejos recursos y reglamentaciones que con toda probabilidad resultarían pesadas para un lector de otra

\footnotetext{
${ }^{20}$ A propósito de esa época se lee también que "Das Intriguenspiel selbst liegt im Charakter der Zeit" (1842, vol. 2: 428).

${ }^{21}$ Por ejemplo el caso de la envenenadora Brinvilliers.
}

Pandaemonium, São Paulo, v. 22, n. 37, mai.-ąo. 2019, p. 51-75 
PIVETTA, C.I. - Perspectivas sobre la justicia francesa del Antiguo Régimen

nación y otra época. En su Novelle, por cierto, no se lee ni una palabra acerca de las presiones ejercidas por los allegados al prior sobre dos testigos cruciales -las criadas de la señora de la Pivardière, en cuyos testimonios se basan las acusaciones contra esta y su confesor-; no es casual que descarte una parte sustancial de lo transmitido en el resto de las versiones, a saber, cómo el hermano del prior, teniente general en Châtillon-sur-Indre, utiliza el poder que le confiere su cargo para conseguir, mediante promesas y amenazas, que ambas testigos, confinadas en una prisión a la que aquel tiene un acceso privilegiado, se retracten en lo que concierne a la culpabilidad de su hermano. Con ello no solo se preserva a la familia del inocente Charost de cualquier contaminación con los métodos espurios para interrogar testigos denunciados en esta obra, sino que el método coercitivo y violento para sonsacar declaraciones queda exclusivamente reservado al juez Bonnet, a quien se describe en los siguientes términos: "Bonnet war (wie es kein Richter sein soll) leidenschaftlich im höchsten Grade, voller Vorurteile, befangen in jeder Art und noch dazu mit der Familie des Augustiners Charost verfeindet" (1985: 763). Al borrar todo rastro de las presiones ejercidas sobre las principales testigos por la influyente familia del prior y atribuir ese cuestionable modo de interrogar, basado en el amedrentamiento y la intimidación, exclusivamente al funcionario judicial encargado de juzgar a los dos inocentes, Hoffmann refuerza una vez más la imagen maniquea del mundo y, gracias a ello, radicaliza más aun que Richer y sus antecesores la crítica a las autoridades, en un caso en el cual cuesta ver claro y deslindar responsabilidades. La omisión intencionada de estos entretelones del viejo proceso permite leer entre líneas una denuncia tácita de la situación prusiana contemporánea, en la medida en que, mediante los cambios efectuados, el escritor alerta tanto mejor acerca de los abusos en los que incurren, en nombre de la justicia, los encargados de administrarla, abusos que el escritor y funcionario berlinés conoce de primera mano. En efecto, desde 1816 este abogado de profesión se desempeña como asesor de la Cámara de Apelación (Kammergerichtsrat) de Berlín y al año siguiente es nombrado comisario de la así llamada comisión para la investigación de maquinaciones demagógicas (Immediat-Comission zur Untersuchung demagogischer Umtriebe), a propósito de cuyos peligrosos métodos Hoffmann advierte en su correspondencia con Hippel: “¡Conociéndome puedes imaginarte mi estado de ánimo al ver cómo se despliega ante mis ojos toda una trama de arbitrariedad infernal, de desvergonzado desacato a todas las leyes, de animosidad personal!... Aquí era hora de conducir a castigar con todo rigor por el camino de la ley. Pero en lugar de eso se tomaron medidas dirigidas no solo contra 
PIVETTA, C.I. - Perspectivas sobre la justicia francesa del Antiguo Régimen

el crimen, sino también contra las convicciones" (cit. en FREUND, 1980: 45; la traducción es nuestra).

En las circunstancias políticas imperantes después de 1815, una época de creciente represión y persecución de los movimientos demócratas y nacionalistas alemanes, la proyección al pasado opera entonces como un rodeo para criticar veladamente lo que la censura impide reprobar de un modo más abierto. Ya en otra novela corta de temática criminal compuesta dos años antes que también transcurre en la Francia de Luis XIV, Hoffmann había adoptado una estrategia similar. Das Fräulein von Scuderi (1819), que aparece el mismo año en el cual los decretos de Karlsbad establecen en Prusia la abolición de la libertad de prensa, lo cual marca el comienzo de la así llamada "persecución de los demagogos", recrea el terror imperante en aquella época de modo tal que en la caracterización que se hace de ella el lector pueda reconocer ciertos rasgos alarmantes de su propio presente. La narración comienza con la descripción de la ola de envenenamientos perpetrados por varias envenenadoras (entre ellas, la marquesa de Brinvilliers, protagonista de otra de las causas célebres narradas por Gayot de Pitaval); esos crímenes funcionan como telón de fondo de la trama principal, centrada en una serie de misteriosos asesinatos nocturnos cometidos contra caballeros parisinos que llevan joyas a sus amadas. Tal situación inicial, que conduce a la propagación del miedo, la superstición y la desconfianza, que "trennte[n] die heiligsten Bande" (1985: 788), proporciona un buen pretexto para la imposición de métodos represivos de persecución de la criminalidad, encarnados en la Cámara Ardiente, cuyo modus operandi es explícitamente condenado en la novela corta: este "Blutgericht" (ibíd.: 820) presidido por La Régnie, un hombre "von garstigem Ansehen und heimtückischem Wesen” (ibíd.: 789) que cegado por el odio y el prejuicio no vacila en torturar a inocentes ni en poner en práctica los métodos más crueles para dar con los culpables, "nahm ganz den Charakter der Inquisition" (ibíd.: 789). Como en Die Marquise de la Pivardiere, aquí también el lector sagaz puede identificar, camuflada en la oscura imagen de las instituciones judiciales de la Francia absolutista, una denuncia indirecta de las arbitrariedades y extralimitaciones del poder policial prusiano de la Restauración.

Pandaemonium, São Paulo, v. 22, n. 37, mai.-ąo. 2019, p. 51-75 
PIVETTA, C.I. - Perspectivas sobre la justicia francesa del Antiguo Régimen

\section{Dos usos del caso La Pivardière desde perspectivas encotradas}

El cotejo de las dos reescrituras analizadas del caso La Pivardière, compuestas por escritores contemporáneos (ambos viven y editan en Berlín, y solo 22 años separan la versión de uno de la del otro), pone de manifiesto grandes diferencias en el uso de la misma materia, que ambos reelaboran a partir de idéntica fuente (Richer): mientras que el narrador de Hoffmann retacea información clave y retarda la explicación de los embrollados hechos, logrando así que la narración resulte tan difícil de desentrañar como el mundo representado, cuyo carácter engañoso e impenetrable se pone así de relieve, el cronista neutral de Alexis introduce sutiles apreciaciones que vehiculizan una discreta justificación del statu quo, camuflada detrás de la pretendida reconstrucción imparcial y ecuánime de lo sucedido. De este modo, bajo la presunta primacía de lo fáctico el editor de Der neue Pitaval ofrece una visión de la Historia entendida como un progreso ineluctable de la civilización, que culmina en la Prusia de sus días. Esta visión está en las antípodas de la del autor de Die Marquise de la Pivardiere, quien, alejándose deliberadamente en varios aspectos de lo documentado (mediante la amplificación de la vida pasada de la protagonista; los nuevos énfasis en los personajes, que acentúan la antítesis entre inocentes y culpables; el agregado de un marco narrativo, por mencionar solo los principales aquí analizados), presenta una vieja historia de modo tal que en ella el lector contemporáneo pueda ver amplificadas, como en un espejo que agranda, ciertas tendencias alarmantes de su propio presente.

\section{Referencias bibliográficas}

ALEXIS, Wilibald ver HÄRING, Wilhelm.

CARPENT, Thierry. Willibald Alexis, intellectuel du «juste milieu». Histoire, Droit et politique dans l'Allemagne du XIX $X^{e}$ siècle. Bern: Peter Lang, 2002.

FREUND, Winfried. Die deutsche Kriminalnovelle von Schiller bis Hauptmann. Paderborn: Schöningh, 1980.

Gayot De Pitaval, François, Histoire de la Pivardière. In: Gayot DE Pitaval, François; Causes célèbres et intéressantes, avec les jugements qui les ont décidées. v. 3. La Haya: Jean Neaulme, 1735, p. 3-92.

HÄRING, Wilhelm [Willibald Alexis]; HITZIG, Julius E. (eds.) Der neue Pitaval. Eine Sammlung der interessantesten Kriminalgeschichten aller Ländern aus älterer und neuerer Zeit. Leipzig: Brockhaus, vol. 1 1842, vol. 2, 1842, vol. 3 1843, vol. 4 1843, vol 6, 1844. [Digitalisat: Bayerische StaatsBibliothek digital]

Hoffmann, E. T. A. Nachtstücke, Klein Zaches, Prinzessin Brambilla, Werke 1816-1820. In: Hartmut Steinecke (ed.) con la colab. de Gerhard Allroggen. Sämtliche Werke. Bd. 3. Frankfurt/Main: Deutscher Klassiker Verlag, 1985. 
PIVETTA, C.I. - Perspectivas sobre la justicia francesa del Antiguo Régimen

LiNDER, Joachim. Der neue Pitaval von Julius Eduard Hitzig und Wilhelm Häring. 1842-1890. Ein Überblick über die Gegenstände und Verfahrensweisen der Darstellung von Kriminalfällen für das 'gebildete Publikum'. Tese (mestrado). Univ. de Múnich, 1982.

RICHER, François. Histoire de la Pivardière. In: RICHER, François. Causes célèbres et intéressantes avec les jugemens qui les ont décidées, rédigées de nouveau par M. Richer, ancien avocat au Parlement. v. 4. Amsterdam: Michel Rhey, 1773, 431-578.

. Geschichte des Herrn de la Pivardiere. In:

Gayot von Pitaval, sonderbare und merkwürdige Rechtsfälle, umgearbeitet und vermehrt von Herrn Richer, Parlamentsadvokat zu Paris. v. 3. Trad. de Carl Wilhelm Franz. Jena: Cuno, 1783, p. 1144.

Recebido em 21 de novembro de 2018

Aceito em 19 de janeiro de 2019

Pandaemonium, São Paulo, v. 22, n. 37, mai.-ago. 2019, p. 51-75 